\title{
NÃO BASTA SER OFICIAL: O PROFESSOR NORMALISTA NAS ESCOLAS DE APRENDIZES MARINHEIROS DO BRASIL E A CULTURA ESCOLAR INSTITUCIONAL
}

\author{
IS NOT ENOUGH TO BE NAVAL OFFICER: NORMALIST TEACHER IN \\ THE SCHOOL OF MARINES APPRENTICES OF BRAZIL AND THE \\ INSTITUTIONAL SCHOOL CULTURE
}

\author{
Antônio de Padua Carvalho Lopes* \\ Rozenilda Maria de Castro Silva**
}

Resumo: Esse texto discute a inclusão do professor normalista no corpo formador das Escolas de Aprendizes Marinheiros do Brasil e a cultura escolar dessa instituição. Baseado na legislação o estudo utilizou como fonte principal os regulamentos dessas escolas, analisando os Decretos: 1517 de 04/01/1855, 9371 de 14/02/1885, 6234 de 14/11/1906, 6582 de 01/08/1907 e 9386 de 28/02/1912. A concepção de cultura escolar fundamenta-se em Julia (2001). A inclusão do professor normalista nessa instituição ocorreu em 1912, fruto da concepção da elite marítima em relação às necessidades formativas do Século XX. Destaca-se uma cultura escolar institucional voltada para a valorização de um professor com sentimentos elevados de patriotismo e de amor à profissão, civilizado, educado moral e intelectualmente, além de detentor de conhecimentos pedagógicos e de experiência didática.

Palavras-chave: Escola de Aprendizes Marinheiros. Professor normalista. Cultura escolar.

\begin{abstract}
This paper discusses the inclusion of normalista teacher trainer in the body of Apprentices Schools Sailors of Brazil and the school culture that institution. Based on the law the study used as the main source regulations these schools, analyzing the Decrees: 1517 of 01/04/1855, 9371 of $02 / 14 / 1885,6234$ of 11/14/1906, 6582 of 08/01/1907 and 9386 of $02 / 28 / 1912$. The concept of school culture is based on Julia (2001). The inclusion of normalista teacher at that institution occurred in 1912, the result of the maritime elite design in relation to the formation of the twentieth century needs. Noteworthy is an institutional school culture focused on the promotion of a teacher with high feelings of patriotism and love

\footnotetext{
* Possui graduação em Licenciatura Plena em Pedagogia pela Universidade Federal do Piauí (1990), Bacharelado em Ciências Sociais pela Universidade Federal do Piauí (1989), mestrado em Sociologia pela Universidade Federal do Ceará (1996) e doutorado em Educação pela Universidade Federal do Ceará (2001). Atualmente é professor adjunto da Universidade Federal do Piauí. Tem experiência na área de Educação, com ênfase em História e Sociologia da Educação, atuando principalmente nos seguintes temas: história da educação, formação de professores, profissão docente, história de instituição educativa e gênero.

** Doutoranda e Mestre em Educação pela UFPI. Especialização em Psicopedagogia pela UFRJ. Especialização em Ensino-Aprendizagem e Graduação em Pedagogia pela UFPI. Membro dos Núcleos: NEHME - Educação, História e Memória; NESC - Educação, Sociedade e Cultura, ambos do PPGED/UFPI. Autora dos livros: História do Teatro em Parnaíba: 1898 a 1999, Companhia de Aprendizes Marinheiros do Piauí - 1874 a 1915 : História de uma Instituição Educativa e A Escola de Aprendizes Marinheiros de Parnaíba. Atualmente é funcionária do Sesc e ocupa a função de Coordenadora Estadual do Projeto Sesc Ler no Piauí atuando na área de Educação de Jovens e Adultos.
} 
for the profession, civilized, educated morally and intellectually, and holder of pedagogical knowledge and teaching experience.

Keywords: School for Sailors. Normalista teacher. School culture .

As Escolas de Aprendizes Marinheiros constituíram uma rede de instituição educativa em sistema de internato, criada no Brasil a partir de 1840, pela Secretaria de Estado dos Negócios da Marinha com o objetivo de formar marinheiros para a Marinha de Guerra. Esse mesmo sistema foi adotado por outros países como Inglaterra, França e Estados Unidos (MARINHA, 1877). Destinadas aos menores pobres, órfãos e desvalidos estas escolas ofereciam educação elementar e profissional, incluindo nesta última, o ensino militar e conhecimentos necessários para a profissão de marinheiro. Inicialmente, denominadas Companhia de Aprendizes Marinheiros, com o Decreto n $^{\circ} 9371$ de 14 de fevereiro de 1885 passaram a denominar-se Escola de Aprendizes Marinheiros.

A primeira Companhia foi instituída na Corte em 1840, a segunda no Pará em 1855, expandindo-se às Províncias da Bahia, Mato Grosso, Pernambuco, Santa Catarina, Maranhão, Rio Grande do Sul, Espírito Santo, Paraná, Ceará, Sergipe, São Paulo, Paraíba, Amazonas, Rio Grande do Norte, Piauí e Alagoas, de modo que no período Imperial somavam dezoito escolas e no período Republicano vinte escolas em todo o País. Atualmente existem apenas quatro Escolas em funcionamento nos Estados do Ceará, Espírito Santo, Pernambuco e Santa Catarina.

Os primeiros estudos desta temática de que se tem conhecimento datam de 1999 sobre os aprendizes da guerra (VENÂNCIO, 1999), e hoje, segundo a nossa pesquisa, existem dezessete trabalhos sobre dez Companhias/Escolas de Aprendizes Marinheiros resultados de estudos realizados em programas de pós-graduação de diversas universidades.

Nesse texto discutiremos, num primeiro momento, a inclusão do professor normalista no corpo formador de marinheiro na Escola de Aprendizes Marinheiros do Brasil. Definimos como corpo formador o conjunto dos funcionários responsáveis pela formação elementar e profissional dos aprendizes nas Escolas de Aprendizes Marinheiros. No segundo momento, discutiremos a cultura escolar dessa instituição, à luz dos conhecimentos a serem ensinados no ensino elementar e as prescrições das práticas na transmissão desses conhecimentos pelo professor normalista.

Baseado na legislação o estudo utilizou como fonte principal os regulamentos das Escolas de Aprendizes Marinheiros, analisando os Decretos: 1517 de 04 de janeiro de 1855, 
9371 de 14 de fevereiro de 1885, 6234 de 14 de novembro de 1906, 6582 de 01 de agosto de 1907 e 9386 de 28 de fevereiro de 1912. A concepção de cultura escolar fundamenta-se em Julia (2001).

\section{“O cargo de professor de primeiras lettras não pode ser exercido por qualquer"}

A citação acima é do relatório de 1910 do Ministro de Estado dos Negócios da Marinha, Joaquim Marques Baptista de Leão, referindo-se as limitações da ação educativa das Escolas de Aprendizes Marinheiros pela ausência de professores com formação pedagógica, frente as possibilidades e efeitos da atuação dos oficiais no ensino das primeiras letras. Percebemos no discurso do Ministro nesse relatório um ideal de professor para essas escolas, o professor normalista: "a pedagogia constitue uma especialidade de cuja necessidade não podem escapar as escolas de aprendizes e á qual não se póde forçar os nossos officiaes" (MARINHA, 1911, p. 37).

Fruto dessa discussão em torno da importância dos conhecimentos pedagógicos e da impossibilidade de realizá-lo na formação dos oficiais, o professor normalista como componente do corpo formado surgiu na legislação das Escolas de Aprendizes Marinheiros do Brasil em 1912.

O Decreto $\mathrm{n}^{\mathrm{o}} 1517$ de 4 de janeiro de 1855 que criou a Companhia de Aprendizes Marinheiros da Província do Pará, instituiu o regulamento do funcionamento dessa Companhia e esse mesmo regulamento serviu para as demais Companhias do Império até início de 1885. Cada companhia teve o seu Decreto de criação que definia para a normatização do seu funcionamento o regulamento do Decreto de 1855. Segundo esse regulamento, o ensino elementar nas Companhias de Aprendizes Marinheiros ficou a cargo do capelão do arsenal que também era responsável pelo ensino religioso ou de um oficial marinheiro com as habilitações necessárias para o exercício da função (BRASIL, 1856). Até então a legislação não fazia referência ao termo professor.

O segundo regulamento dessas escolas veio com o Decreto 9371 de 14 de fevereiro de 1885 e ao lado do capelão que continuou com o ensino religioso surgiu o professor de primeiras letras para ministrar o ensino elementar. (BRASIL, 1886). De acordo com Castro, o professor de primeiras letras, recebia "gratificação anual de 1:200\$000 e [...] o Capelão uma gratificação de 1:000\$000 pelo ensino religioso e mais 504\$000 de soldos extras por outras funções no quartel, totalizando um vencimento anual de 1:504\$000." (CASTRO, 2013, p. 84). 
Sobre a presença de professores de primeiras letras na Escola de Aprendizes Marinheiros do Piauí, a mesma autora informa:

Conseguimos verificar a presença do professor de primeiras letras na Escola em poucos momentos. Em 1889, o professor Francisco Antonio d'Avila Ozório afastou-se por três meses, acometido de beribéri e foi substituído pelo professor Francisco Baptista de Castro. [...] Euclides Godofredo da Silva Miranda foi outro professor que em 1889, interinamente, ocupou cargo na Escola em substituição ao definitivo por motivo de licença. (CASTRO, 2013, p. 84).

O regulamento de 1885 não faz referência à formação do professor de primeiras letras nem às suas atribuições e forma de acesso ao exercício do cargo. O próximo regulamento das Escolas de Aprendizes Marinheiros foi o do Decreto 6234 de 14 de novembro de 1906. Nesse novo regimento "a regencia de algumas aulas de instrução elementar" ficou a cargo dos instrutores responsáveis pelo ensino profissional, (BRASIL, 1907a, p. 1049). Na lista do pessoal das Escolas de Aprendizes Marinheiros não constava o professor. Nas disposições diversas do Regulamento o Art. 58 registra que "são conservados os logares de professores [...] actualmente existentes" ((BRASIL, 1907a, p. 1053) o que apresenta indícios de que seriam mantidos nas Escolas os professores de primeiras letras do regulamento anterior, considerando também que os instrutores respondiam pela regência de algumas aulas e não de todo o ensino elementar.

Em 1907, as Escolas de Aprendizes Marinheiros tiveram um novo regulamento com o Decreto $n^{\circ} 6582$ de $1^{\circ}$ de agosto e dividiram-se em duas categorias: escolas primárias ou de $1^{\circ}$ grau, com duração de um ano e escolas-modelo ou de $2^{\circ}$ grau, com duração de dois anos. No quadro de pessoal das escolas primárias tinha um professor e dois professores para as escolasmodelo, sendo um para o primeiro ano e o outro para o segundo ano. Pela primeira vez aparece na legislação a atribuição dos professores: “[...]a regencia do ensino de conformidade com as instrucções, programmas e horarios determinados pelo Ministro da Marinha", Art. 52, (BRASIL, 1907b, p. 1446). A sua nomeação se dava por portaria e por prazo indeterminado, "podendo ser demittido em qualquer época, por conveniencia do ensino, a juízo do Ministro da Marinha”. (BRASIL, 1907b, p. 1450).

Localizamos um contrato de 1911 da Escola Modelo-Modelo do Rio Grande do Sul com um professor do Ensino Elementar apresentando uma forma de acesso do professor à referida Escola, por convite, conforme transcrição a seguir: 
Termo de contracto celebrado com o Cidadão Carlos Gonçalves de Assumpção para exercer o cargo de professor de ensino elementar.

Aos onze dias do mez de Março do anno de mil novecentos e onze na Escola de Aprendizes Marinheiros do Rio Grande do Sul, a convite do Sr. Capitão de Corveta Commandante Mario Vieira Cortez, compareceu o cidadão Carlos Gonçalves de Assumpção, natural deste Estado, solteiro com vinte e tres anos de idade e em virtude de ordem telegráfica da Inspetoria de Marinha datada de seis do corrente mez, foi contractado para exercer o cargo de professor de ensino elementar desta Escola, por tempo indeterminado, percebendo a gratificação mensal de cento e dezeseis mil seiscentos e sessenta e seis reis (116\$666) ficando sujeito as exigencias do Regulamento das Escolas de Aprendizes Marinheiros approvado por Decreto N. 6582 de $1^{\circ}$ de Agosto de 1907. O presente contracto poderá ser rescindido quando assim o governo julgar conveniente não cabendo ao contractado direito á reclamação alguma. [...] (ESCOLA-MODELO, 1911, grifo nosso).

No discurso dos relatórios ministeriais era necessário modernizar o corpo formador dessas escolas para atender às novas exigências formativas do marinheiro do Século XX. Conforme opinião do Ministro de Estado dos Negócios da Marinha, Alexandrino Faria de Alencar, "o marinheiro de guerra não é mais o marujo do passado ou do período de transição, mas sim um especialista mecanico, além de marujo e de soldado. Sua formação sob esse triplice aspecto exige methodo, tempo e um terreno preparado". (MARINHA, 1914, p.193).

O Ministro de Estado dos Negócios da Marinha, Joaquim Marques Baptista de Leão, em seu relatório de 1910, referindo-se às inconveniências das Escolas de Aprendizes Marinheiros informa que tratará de reduzir todas as escolas a um só programa de ensino primário, sugerindo que:

[...] o pessoal administrativo e docente deve ser modificado. O cargo de professor de primeiras lettras não póde ser exercido por qualquer; é preciso, além da natural inclinação, estudo e methodo. Muitos dos officiaes enviados como instructores não podem, por falta de um ou mais predicados citados, desempenhar cabalmente a sua missão, embora isso possa ser feito por outrem com preparo scientifico inferior ao seu. A pedagogia constitue uma especialidade de cuja necessidade não podem escapar as escolas de aprendizes e á qual não se póde forçar os nossos officiaes. (MARINHA, 1911, p. 37).

Destaca-se nessa fala o reconhecimento da necessidade da pedagogia como componente da formação do professor da escola, atendendo a ampliação das necessidades formativas. Assim, com o objetivo de educar moral e intelectualmente os aprendizes marinheiros, tendo além da "natural inclinação", estudo e método, o professor normalista foi incluído no corpo 
formador das Escolas de Aprendizes Marinheiros, para ministrar o ensino elementar, através do regulamento do Decreto 9386 de 28 de fevereiro de 1912.

Esse regulamento normatizava o funcionamento das Escolas de Aprendizes Marinheiros e de Grumetes, escola que atendiam os menores ao deixarem as Escolas de Aprendizes Marinheiros. Consideradas de primeiro grau, as Escolas de Aprendizes Marinheiros tinham a duração de dois anos e como finalidade "educar e preparar os menores para cursarem as escolas de grumetes", Art. $4^{\circ}$ (BRASIL, 1912, p. 250). As Escolas de Grumetes ou de segundo grau, com duração de um ano, destinavam-se a concluir a formação elementar das Escolas de Aprendizes Marinheiros e a ministrar ensino voltado para "as noções de especialidades taes como artilheiro, torpedista, timoneiro, signaleiro e foguista, afim de averiguar as aptidões e dar também o preparo indispensavel aos que não possam ser especialistas." Art. 5 (BRASIL, 1912, p. 250). O ano letivo nas duas escolas, era dividido em duas séries. As duas escolas ofereciam ensino elementar, de especialidades - profissão do marinheiro e ensino acessório voltado para a formação militar (BRASIL, 1912).

Nas Escolas de Aprendizes Marinheiros, o ensino elementar, segundo a legislação de 1912 era ministrado pelo professor normalista e o objetivo da formação era o desenvolvimento do aprendiz no conjunto de suas faculdades. Enquanto o ensino acessório e de especialidades eram ministrados pelos oficiais e mestres com o objetivo de preparar as aptidões profissionais dos alunos para o desempenho de suas funções de marinheiro.

O acesso ao cargo de professor normalista nas Escolas de Aprendizes Marinheiros se dava mediante concurso de prova escrita, de tema sorteado, com duração de duas horas e prova prática pública com duração de uma hora. Do ponto de vista da cultura profissional desejada, "o exame ou o concurso definem, tanto na forma das provas como nos conteúdos dos saberes propostos aos candidatos, a base mínima de uma cultura profissional a se possuir." (JULIA, 2001, p. 30). Para concorrer à vaga de professor do ensino elementar nessas escolas era necessário atender aos seguintes requisitos, comprovadamente, conforme Art. 25:

a) ser diplomado por qualquer Escola Normal do Brazil;

b) ter mais de 21 annos de idade;

c) ter pelo menos tres annos de exercicio no magisterio;

d) ser cidadão brasileiro nato ou naturalizado;

e) ter sido vaccinado ou affetado de variola; 
f) não soffrer molestia repugnante ou contagiosa, ou ter qualquer defeito physico que o impossibilite para o magistério; (BRASIL, 1912, p. 253).

Assim, além do diploma da Escola Normal, a exigência de "pelo menos três anos de exercício no magistério" mantinha a ideia da formação como resultado da experiência, conjugando formação escolar e prática como docente, indicando não considerar suficiente apenas a formação na Escola Normal, resguardando, desse modo, a prática como base formativa relevante.

Estavam exclusos do concurso "os que houverem sido condennados por sentença, passada em julgado, em processo por acto ofensivo á moral ou ás leis da Republica”, $\S 2^{\circ}$, do Art. 28, e também "os que estiverem sob acção de processo por qualquer crime previsto no Codigo Penal," $\S 3^{\circ}$ do Art. 28, (BRASIL,1912, p. 254). A mesa julgadora do concurso era composta de cinco pessoas: o Diretor da Escola de Aprendizes Marinheiros, na função de presidente, dois oficiais e dois professores da própria escola ou de alguma escola oficial federal ou estadual. O secretario era um dos professores a ser indicado pelo presidente da banca. Os candidatos eram avaliados numa escala de notas que variava de um a seis, com os seus respectivos conceitos: " um - a soffrivel, dous - a regular, tres - a bôa, quatro - a muito bôa, cinco - a optima, seis - a optima com louvor”. (BRASIL,1912, p. 255).

Concluído o concurso, o presidente da mesa julgadora deveria encaminhar ao Ministro da Marinha uma cópia da ata, provas e relatório com a indicação do candidato mais votado para a nomeação. Entretanto, "o ministro da Marinha não ficará, porém, obrigado a nomear o candidato proposto. A nomeação poderá recahir nelle ou no segundo dos concorrentes mais votados, quando comparecerem ao concurso mais de dous candidatos" (BRASIL, 1912, p. 253). A nomeação dos professores aprovados se dava por portaria. A quantidade de professores normalistas por Escola de Aprendizes Marinheiros era na proporção de um professor para cada grupo de 40 a 50 alunos.

O Art. 133 das Disposições Transitórias do regulamento em estudo, informa que:

O primeiro provimento dos logares de professores do curso elementar, nas escolas de aprendizes marinheiros de $1^{\circ}$ gráo [...] será feito livremente pelo ministro da Marinha, devendo, porém, recahir a nomeação em professores normalistas com pratica de tres anos, pelo menos, de magisterio. (BRASIL, 1912, p. 271). 
O Art. 134 complementa a informação acima, acrescentando que "as vagas, que depois se forem verificando, serão preenchidas de acordo com as disposições deste regulamento." (BRASIL, 1912, p. 271). O porquê dessa abertura para a livre contratação inicial de professores normalistas do ensino elementar nestas Escolas, pelo Ministro da Marinha, sem concurso, pode ser compreendido pelos indícios apresentados no Art. 135: "para a primeira organização da escola [...] da Capital Federal, que se tornará escola modelar para as demais, o ministro da Marinha commissionará, por dous annos, um professor de reconhecida competência, do corpo ensinante da Capital Federal ou dos Estados da União." (BRASIL, 1912, p. 271).

A Escola da Capital Federal era considerada modelo para todas as escolas de aprendizes do país. A legislação apresenta uma exigência com a preparação técnica dos professores normalistas visando uma uniformização do ensino elementar nas Escolas de Aprendizes Marinheiros. Além de ser formado por uma Escola Normal e ter pelo menos três anos de experiência no magistério, conforme critério seletivo, cada professor das outras escolas era "obrigado a acompanhar, durante dous mezes, pelo menos, o ensino ministrado na escola da Capital Federal, afim de poder aplicar, no ensino da classe que reger, os mesmos methodos e processos que tiver observado, uniformizando-se assim o ensino". Art. 136 (BRASIL, 1912, p. 271). A legislação previa o recebimento de um grupo de oito professores de cada vez, com revezamento de um professor de cada escola.

Segundo o mapa geral das Escolas de Aprendizes Marinheiros, datado de $1^{\circ}$ de janeiro de 1914, anexo do relatório ministerial de 1913 (MARINHA, 1914), nesse período, das vinte escolas do país, dezenove tinham professores normalistas. A exceção era a Escola de Aprendizes Marinheiros do Mato Grosso que tinha um professor auxiliar de ensino, contava com apenas 6 aprendizes marinheiros e nos últimos anos o seu efetivo não chegou a vinte alunos. Nas Escolas do Amazonas, Pará, Maranhão, Ceará, Rio Grande do Norte, Paraíba, Pernambuco, Alagoas, Sergipe, Rio de Janeiro (Campos), Capital Federal, São Paulo, Paraná, Santa Catarina e Rio Grande do Sul tinham dois professores normalistas em cada uma. Nas Escolas de Aprendizes Marinheiros do Piauí e Espírito Santo tinha um professor normalista. Na Escola de Minas Gerais tinham três professores normalistas e na Escola da Bahia quatro professores normalistas.

O regulamento de 1912 apresenta uma distinção com relação aos salários dos professores normalistas dando indícios de uma possível hierarquização dessas escolas e, 
portanto, de seus docentes. Segundo o Art. 91, "os professores normalistas das escolas de aprendizes da Capital Federal, Santos, Bahia, Pernambuco, Pará, Rio Grande do Sul e Minas Geraes perceberão annualmente 6:000\$; os das outras 4:800\$00 [...]”, (BRASIL, 1912, p. 265). O parágrafo único desse artigo explica que "esses vencimentos serão contados: dous terços, como ordenado e um terço como gratificação pro-labore” (BRASIL, 1912, p. 265).

Discutida a inclusão do professor normalista no corpo formador de marinheiro nas Escolas de Aprendizes Marinheiros do Brasil passaremos agora a falar sobre a cultura escolar dessa instituição, especificamente os conhecimentos a serem ensinados no ensino elementar e as prescrições das práticas na transmissão desses conhecimentos pelo professor normalista.

\section{"A marcha natural do espírito para a acquisição do saber"}

De acordo com o regulamento do Decreto 9386 de 28 de fevereiro de 1912 o ensino elementar das Escolas de Aprendizes Marinheiros a ser ministrado pelo professor normalista, compreendia as seguintes matérias:

1) lingua materna;

2) arithmética (noções e operações fundamentaes);

3) geometria prática;

4) systema metrico decimal;

5) geografia do Brazil e noções muito simples de geographia geral. Noções elementares de phenomenos atmosphericos;

6) historia do Brazil;

7) educação cívica;

8) desenho;

9) noções de sciencias naturaes e de hygiene;

10) lições gerais. Art. 14 (BRASIL, 1912, p. 251-252)

A música estava incluída no currículo do ensino elementar mais ficava a cargo do mestre de música. O Programa para as Escolas de Aprendizes Marinheiros e de grumetes anexo ao regulamento do Decreto 9386 de 28 de fevereiro de 1912, referindo-se ao tratamento que deveria ser dado pelo professor normalista no desenvolvimento das matérias acima, apresenta princípios pedagógicos que valoriza "a marcha natural do espírito para a acquisição do saber: [...] [reconhecendo que] o primeiro acto importante da consciencia é a percepção sensitiva - as primeiras acquisições do saber foram sempre por meio dos sentidos." (BRASIL, 1912, p. 272), ou seja, "primeiro o objeto - a idéa. - depois a palavra que a representa: percepto, para produzir o concepto.” (BRASIL, 1912, p. 272). Dessa forma, o professor só 
deveria ensinar fatos e ideias associados com outros fatos e ideias já assimilados pelos alunos.

Pelos princípios pedagógicos apresentados acima, há indícios da influência das formulações teóricas de Pestalozzi na prática formativa das Escolas de Aprendizes Marinheiros. Sobre o assunto Freitas e Zanatta informam que "[...] Pestalozzi formulou seu método de ensino com alguns princípios: partir do conhecido ao desconhecido; [...] da visão intuitiva à compreensão geral. A base desse método foi a idéia de percepção sensorial. [...]" (FREITAS; ZANATTA, 2006, p. 3) E continuam as autoras:

[...] Suas idéias demarcaram uma vertente da pedagogia tradicional denominada Pedagogia Intuitiva, cuja característica básica é oferecer dados sensíveis à percepção e observação dos alunos. Essa pedagogia fundamentava-se na psicologia sensualista, cujos representantes afirmavam que toda a vida mental se estrutura baseando-se nos dados dos sentidos. Tal como Rousseau, Pestalozzi concebia a educação como processo que deve seguir a natureza e os princípios da liberdade, da bondade inata do ser e da personalidade individual da criança. [...] (FREITAS; ZANATTA, 2006, p. $3)$.

O Programa descreve minuciosamente os conteúdos juntamente com todos os passos que o professor normalista deverá seguir na sua prática formativa nas Escolas de Aprendizes Marinheiros, na matéria língua materna, na $1^{\mathrm{a}}$ e $2^{\mathrm{a}}$ Séries do $1^{\mathrm{o}}$ Ano, com duração de um ano letivo, conforme transcrevemos abaixo:

$1^{\circ}$. Palestra com os alumnos sobre um objecto qualquer (tinteiro, canivete, livro, etc.), sobre uma flôr, uma fructa ou uma estampa, escrevendo-se no quadro-negro as sentenças enunciadas. Leitura das sentenças escriptas. Sublinhar as phrases no corpo das sentenças e destacal-as depois, mandando lel-as de novo. Analysar as sentenças, perguntando aos alumnos: quem é que? Que é que? e escrever as respostas em columna vertical, reproduzindo o sujeito, o verbo e o predicado ou o objecto de cada sentença, e mandando lel-os de novo.

Escrever as sentenças, mudando ora o sujeito, ora o verbo, ora o predicado ou o objeto. Escrever cada sentença, palavra por palavra, em coluna vertical. Pronunciar vagarosa e naturalmente cada palavra e cada sentença, educando o ouvido do alumno no conhecimento dos sons constitutivos de cada vocabulo. Dar grupo de palavras similares, mudando e augmentando uma ou outra lettra para formar novas palavras; ex.: espada, escada; pato, gato, rato, prato, grato, etc. Destacar da sentença, quando escripta em coluna vertical, uma das palavras e mandar os alumnos dizerem outras palavras que tenham o mesmo som inicial. Ex.: boneca, bocca, bola, bôa, etc. escrevendo-as em séries, umas debaixo das outras, no quadro-negro. Exercícios sobre palavras derivadas, similares, e rimas, ex.: laranja, laranjeira; casa, capa; bola, rola, 
mola, etc. Analyse das palavras em seus elementos: syllabas e letras. Formação de novas palavras com as syllabas de duas ou mais palavras já conhecidas: ex.: boneca, tapete, formando bocca, bote, bota, boné, cabo, caneca, cata, caneta, peteca, peta, etc.

Conhecimento do alfabeto na sua ordem classica.

$2^{\circ}$. Leitura na cartilha analytca, de A. Barreto, seguindo em cada lição, o mesmo processo acima.

$3^{\circ}$. Leitura expressiva no primeiro livro de Aprigio Gonzaga, ou primeiro livro de Sarah arnold, e interpretação do trecho todo.

$4^{\circ}$. Leitura do primeiro livro da série Puiggari-Barreto, ou primeiro livro de João Kopke. (BRASIL, 1912, p. 273-274).

O Programa apresenta para "linguagem escripta":

$1^{\circ}$ Copiar palavras e sentenças das lições de leitura, dadas no quadro-negro; $2^{\circ}$. Copiar palavras e sentenças de cartões impressos em typo manuscripto vertical.

$3^{\circ}$. Copiar palavras, sentenças e periodos do livro de leitura.

$4^{\circ}$. Dictados de palavras e sentenças do livro de leitura, e de palavras similares e rimas.

$5^{\circ}$. Descripções muito simples de assumptos vistos em estampas.

$6^{\circ}$. Copiar palavras e sentenças com cartões de lettras impressas. (BRASIL, 1912, p. 274).

E para a "linguagem oral":

$1^{\circ}$. Palestras sobre objectos, flores, fructas, sementes, artefactos, estampas, scenas naturaes, reproduzindo um dos alumnos o assumpto tratado.

$2^{\circ}$. Descrição oral de scenas vistas no cinamatographos, ou de contos narrados ou lidos em classe pelo professor.

$3^{\circ}$. Recitação de poesias aprendidas de outiva ou de cópias fornecidas pelo professor. (BRASIL, 1912, p. 274).

Segundo o regulamento de 1912, a principal finalidade das funções do professor normalista, nas Escolas de Aprendizes Marinheiros “é educar [...] moral e intellectualmente os seus alumnos, desenvolvendo-lhes, ao mesmo tempo, sentimentos elevados de dignidade, de patriotismo e de amor á profissão a que se destinam”. (BRASIL, 1912, p. 263). Essa educação moral e intelectual deveria ser viabilizada pelas atribuições do professor normalista na "regência de suas classes e aulas [...] de conformidade com as instrucções, programas e horarios do regimento interno", (BRASIL, 1912, p. 263), incluindo outras atribuições determinadas no regulamento dessas instituições, tais como a aplicação de penalidades aos aprendizes: "admoestação, reprehensão em classe, eliminação do nome do quadro de honra, abaixamento das notas de comportamento e privação de recreio", Art. 59 (BRASIL, 1912, p. 
258); participação na composição do Conselho de Disciplina da Escola, juntamente como o diretor, vice-diretor e oficial para julgamento dos alunos e indicação de exclusão dos casos incorrigíveis.

O Art. 79 do regulamento do Decreto 9386 de 28 de fevereiro de 1912, apresenta uma lista das exigências de outras práticas do professor normalista no interior dessas escolas, no sentido de viabilizar a educação moral desejada na formação dos aprendizes marinheiros, conforme apresentaremos a seguir:

[...] $\S 2^{\circ}$ dar exemplo de polidez e moralidade em seus actos, tanto nas escolas como fóra dellas; $\S 3^{\circ}$ Dar aula todos os dias uteis, na classe de sua regencia, com a maior dedicação e solicitude, preenchendo o tempo marcado para esse fim. $\S 4^{\circ}$ Manter, em suas respectivas classes, a necessaria disciplina, baseada sempre no respeito mutuo e na consciencia do dever, observando rigorosamente o regimento interno. [...] § 11 Achar-se no estabelecimento, todos os dias uteis, 15 minutos antes do inicio das aulas e dele só retirar-se depois de terminado o seu trabalho. [...] § 15 Exercer a vigilância do recreio, quando for designado pelo director. [...] § 19 Não abandonar a respectiva classe, á hora do trabalho, sem previa licença do director; § 20 Não se ocupar, durante as horas de exercicio, em objecto extranho ao ensino da classe. (BRASIL, 1912, p. 263-264).

As incumbências listadas acima demonstram a postura moral exigida do professor normalista, tanto fora como dentro das Escolas. Atitudes gentis, cortesia, civilidade, pontualidade e disciplina eram quesitos necessários à profissão. "Dar aula todos os dias úteis [...] com a maior dedicação e solicitude, preenchendo o tempo marcado para esse fim" deveria ser, para os aprendizes, exemplo de amor e dedicação à profissão. O ensino elementar, segundo a legislação, ocorria diariamente de segunda a sábado, cinco horas por dia, divididas em dois momentos: "um, de 8 horas ás 10,30 da manhã, e outro, de 12 ás 2:30 da tarde" (BRASIL, 1912, p. 272). O primeiro momento do tempo escolar dos dois turnos eram ocupados pelas disciplinas que exigiam maior esforço intelectual. $\mathrm{O}$ ano letivo iniciava no dia 15 de janeiro e finalizava no dia 15 de dezembro, com férias escolares de inverno no período de 10 a 30 de junho. As aulas cessariam aos domingos e nos dias 24 de fevereiro, 21 de abril, 3 e 13 de maio, 14 de julho, 7 de setembro, 12 de outubro, 2 e 15 de novembro, Art. 19 e 20 (BRASIL, 1912). A abertura e o encerramento do ponto, diariamente, do professor normalista, era uma atribuição do Diretor das Escolas de Aprendizes Marinheiros, no acompanhamento da pontualidade e do cumprimento do horário de trabalho desse professor. 
O Art. 79 apresenta uma outra lista das exigências de práticas do professor normalista voltadas para a formação intelectual dos aprendizes:

[...] § 12 Ensinar todas as matérias do programma, e todo o programma, seguindo escrupulosamente os horarios adoptados, e dando lições directas, em que solicite a maior colaboração do alumno, de modo a promover o adiantamento uniforme e geral da classe.

$\S 13$ Ministrar o ensino da maneira mais pratica e intuitiva possível, guiando os alumnos a educarem-se sem fadigas nem violencias intellectuaes desnecessarias. § 14 Fugir a todo o processo didactico que se dirija exclusivamente ao exercicio da memoria, ficando-lhes formalmente prohibido o ensino por meio de apontamentos, dictados, etc. ou por outro qualquer systema que torne o ensino mecanico e fastidioso. [...] $§ 22$ Utilizar-se somente dos livros didacticos que forem adoptados para uso de seus alumnos. (BRASIL, 1912, p. 263-264).

Nos princípios pedagógicos a ser observado pelo professor normalista no programa para as Escolas de Aprendizes Marinheiros do Regulamento de 1912, é orientado que o professor, substitua "o ensino por meio de prelecções", e proceda de forma que "o próprio alumno exerça, para aprender, toda a atividade que lhe é inerente e natural". Que o professor apenas guie o aluno "na descoberta da verdade". (BRASIL, 1912, p. 272). Trata-se de uma concepção pedagógica que valoriza a percepção sensitiva, a aquisição do saber por meio dos sentidos e valoriza as contribuições da psicologia, informando que "todo o processo de ensino deve harmonizar-se com a ordem e leis do desenvolvimento individual" (BRASIL, 1912, p. 273).

Com relação ao acompanhamento da assimilação do conhecimento dos aprendizes, os princípios pedagógicos do programa orientam que:

O gráo de desenvolvimento mental do alumno avalia-se pelo gráo de sua expressão: - na linguagem mimica, oral e escripta, na leitura e no desenho. Para desenvolver a expressão, o professor terá de fazer em todas as disciplinas, as perguntas seguintes: - Que? Qual? Por que? Como? (BRASIL,1912, p. 273).

A prática formativa do professor normalista era orientada para a utilização do processo "analytico-syntetico", ou seja, o professor deveria partir do todo para as partes e depois reconstituir as partes para compor o todo. Os princípios pedagógicos detalham o passo a passo a ser desenvolvido: "Ex.: no ensino da leitura, ensinará, primeiro, a historieta, depois as sentenças, as phrases, as palavras, as syllabas, as letras, reunindo depois as syllabas para 
formar palavras, e estas para formar as sentenças, que são a unidade do pensamento." (BRASIL, 1912, p. 273). O princípio básico da educação formal das Escolas de Aprendizes Marinheiros, segundo esse regulamento, considera que "aquillo que a principio se aprende e se faz com esforço e pena - conscientemente, portanto - os orgãos e o espirirto realizam depois, devido ás repetições, automaticamente."

Além das já citadas, o Art. 79 ainda apresenta outras atribuições da prática do professor normalista dentro das Escolas de Aprendizes Marinheiros revelando suas múltiplas funções, no auxílio de outros profissionais dessas escolas, como o médico, mestre de música e de ginástica:

$\S 5^{\circ}$ Conservar, com todo o cuidado, os moveis, livros e mais objetos escolares de sua classe, não podendo distrahil-os para outros misteres.[...]

$7^{\circ}$ Cumprir todas as obrigações impostas por este regulamento, assim como as instrucções do diretor da escola.

$\S 8^{\circ}$ Fazer parte das bancas examinadoras do concurso a que se refere este regulamento.

$\S 9^{\circ}$ Fornecer, mensalmente, ao director, um mappa contendo as médias de applicação e comportamento de seus respectivos alumnos.

$\S 10$ Auxiliar o medico do estabelecimento nos exames pedologico dos pretendentes á matricula, classificando-os collocando-os na classe de acordo com o gráo de sua vista, ouvido, etc.[...]

$\S 17$ Comparecer ás festas escolares [...]

$\S 18$ Communicar ao diretor, justificando o motivo, as faltas que, porventura, tenha de dar, isto com a necessária antecedência.[...]

$\S 21$ Levar ao conhecimento do diretor, ou do vice-director, qualquer facto anormal que se dê na classe, durante as horas de aula.[...]

$\S 23$ escripturar o livro de chamada dos alumnos da classe, e fazer a chamada diariamente.

$\S 24$ Assistir aos exercicios de musica e de gynnastica auxiliando a disciplina durante essas aulas.

O regulamento de 1912 normatizava as penalidades que o professor normalista sofreria se não cumprisse as suas atribuições prescritas nesse regulamento: “ $1^{\circ}$, admoestação ${ }^{1} ; 2^{\circ}$, reprehensão; $3^{\circ}$, suspensão do exercicio do cargo por 15 dias, e na reincidencia , por 30 dias; 4 , demissão", Art. 81, (BRASIL, 1912, p. 264). A demissão era feita pelo Ministro da Marinha através de ofício e as demais penalidades eram aplicadas pelo Diretor da Escola, evitando aplicá-las na presença dos aprendizes para "não diminuir o prestigio moral do professor” Art. 82, (BRASIL, 1915, 264).

\footnotetext{
${ }^{1}$ Chamar a atenção de alguém por alguma irregularidade disciplinar; repreensão benevolamente feita. (REIS, 1947, p. 24).
} 
Competia ao Diretor das Escolas de Aprendizes Marinheiros para verificar o cumprimento dos objetivos das escolas "visitar amiudadas vezes as aulas [...] acompanhando tanto quanto possivel o ensino ministrado aos aprendizes e poder assim certificar-se pessoalmente do modo de proceder do pessoal docente," [...] $\S 4^{\circ}$ do Art. 74 (BRASIL, 1912, p. 261). O vice-diretor também desempenhava a função de fiscalizar as Escolas e as obrigações de cada funcionário.

As Escolas de Aprendizes Marinheiros, segundo a legislação de 1912, seriam equipadas com novos espaços, tais como biblioteca com obras modernas de psicologia, pedagogia experimental, livros recreativos para os alunos e professores; galeria histórica e anfiteatro para a educação moral e artísticas dos aprendizes. Percebe-se, assim, nas prescrições da legislação o desejo de, em conjunto com esse aparato, constituir um novo sujeito (o professor normalista), reconhecer os conhecimentos pedagógicos como importantes e modificar os espaços educativos das escolas.

\section{Considerações Finais}

Setenta e dois anos após a criação da primeira Companhia de Aprendizes Marinheiros a legislação incluiu o professor normalista nestas escolas, como conquista da elite marítima frente às necessidades formativas institucionais do Século XX. Passando pelo capelão, oficiais e professores sem identificação da formação, o ensino elementar conquistou o seu espaço dentro das Escolas de Aprendizes Marinheiros, não só na legislação, mas na efetividade da presença do professor normalista como demonstrou o relatório ministerial de 1913 e registrou o Ministro da Marinha de 1910, Joaquim Marques Baptista de Leão: “o cargo de professor de primeiras lettras não póde ser exercido por qualquer."

Martins, informa que "a busca de um profissional da educação de acordo com os novos princípios de urbanidade, um civilizador, estava presente nas discussões e reformas educacionais do final do século XIX e início do século XX.” (MARTINS, 2009, p. 180). Só nas Escolas de Aprendizes Marinheiros de acordo com mapa geral do pessoal das escolas de $1^{\text {o }}$ de janeiro de 1914 tinham trinta e nove professores normalistas. É possível que o cargo de professor normalista nas Escolas de Aprendizes Marinheiros tenha sido ocupado por civis, o que justifica tamanha lista de obrigações na legislação, voltada para esse profissional. Por ser um trabalho num ambiente militar de formação militar, "a cultura escolar desemboca aqui no remodelamento dos comportamentos.”( JULIA, 200, p. 22). 
Pela legislação das Escolas de Aprendizes Marinheiros de 1912, fica evidente, na prescrição dos conhecimentos a serem ensinados, no ensino elementar e nas práticas da transmissão desses conhecimentos, pelo professor normalista, uma cultura institucional voltada para a formação de um profissional com sentimentos elevados de dignidade, de patriotismo e de amor à profissão, civilizado, educado moral e intelectualmente à luz da modernidade de seu tempo.

\section{Referências Bibliográficas}

BRASIL, Colleçção das leis do Imperio do Brasil de 1855. Tomo XVIII, Parte I. Rio de Janeiro: Typographia Nacional, 1856. Disponível em: http://www2.camara.leg.br/atividadelegislativa/legislacao/publicacoes/doimperio/colecao5.html. Acesso em: 04 dez. 2015.

Collecção das Decisões do Governo do Imperio do Brazil de 1885. Rio de Janeiro:

Imprensa Nacional. 1886.Disponível em: http://www2.camara.leg.br/atividadelegislativa/legislacao/publicacoes/doimperio/colecao8.html. Acesso em: 04 jan. 2016.

. Collecção das Leis da República dos Estados Unidos do Brazil de 1906. Rio de

Janeiro: Imprensa Nacional, v. II, 1907a. Disponível em:
http://www2.camara.leg.br/atividade-

legislativa/legislacao/publicacoes/republica/colecao2.html. Acesso em: 02 fev. 2016.

.Indice dos actos do poder executivo 1907b. Disponível em: $<$ http://www2.camara.leg.br/atividade

legislativa/legislacao/publicacoes/republica/colecao2.html>. Acesso em 08 dez. 2015.

. Collecção das Leis da Republica dos Estados Unidos do Brazil de 1912 -

Volume I. Rio de Janeiro: Imprensa Nacional. 1915. Disponível em: $<$ http://www2.camara.leg.br/atividade

legislativa/legislacao/publicacoes/republica/colecao3.html>. Acesso em 09 dez. 2015, 21:30.

CASTRO. Rozenilda. A escola de aprendizes marinheiros de Parnaíba. $2^{a}$ ed. Teresina: EDUFPI, 2013.

ESCOLA-MODELO, Termo de contrato da Escola-Modelo do Rio Grande do Sul. 1911. Serviço de Documentação da Marinha, Arquivo Histórico, Rio de Janeiro.

FREITAS, Raquel A. M. da M.; ZANATTA, Beatriz Aparecida. O legado de Pestalozzi, Herbart e Dewey para as práticas pedagógicas escolares. In: IV Congresso Brasileiro de 
História da Educação. A Educação e seus Sujeitos na História, 2006. Goiânia/GO. Anais... Goiânia/GO: CBHE, 2006.

JULIA, Dominique. A cultura escolar como objeto histórico. Revista Brasileira de História da Educação, n.1, p.9-43, jan/jun, 2001. Disponível em: <http://www.rbhe.sbhe.org.br/index.php/rbhe/article/view/273/281>. Acesso em: Dia 15 fev, 2015, 09:27.

MARINHA. Relatório apresentado pelo Capitão Tenente Luiz Philippe de Saldanha da Gama sobre a eschola naval de Annapolis, academia militar de West-Point, eschola de torpedos de New-Port e instituição de aprendizes marinheiros dos Estados-Unidos. Rio de Janeiro: Typographia Nacional, 1877.

Relatório ministerial. Rio de Janeiro: Imprensa Nacional, 1911. Serviço de Documentação da Marinha, Arquivo Histórico, Rio de Janeiro.

.Relatório ministerial. Rio de Janeiro: Imprensa Nacional, 1914. Serviço de Documentação da Marinha, Arquivo Histórico, Rio de Janeiro.

MARTINS, Angela Maria Souza. Breves reflexões sobre as primeiras escolas normais no contexto educacional brasileiro, no Século XIX. Revista HISTEDBR On-line, Campinas, n.35, p. 173-182, set. 2009. Disponível em: http://www.histedbr.fe.unicamp.br/revista/edicoes/35/. Acesso em: 12 mar. 2016. REIS, Amphiloquio. Dicionário técnico de marinha. Rio de Janeiro: [s.n.], 1947. VENANCIO, Renato Pinto. Os aprendizes da guerra. In: PRIORE, Mary Del. História das crianças no Brasil. São Paulo: Contexto, 1999. 